\title{
Bibliometric Analysis of Nursing Articles Focused on Health Education
}

\author{
Carla Monique Mourao, Ana Izabel Nicolau, Marília Marques, \\ Ana Fátima Fernandes, Maria Josefina Silva, Ana Karina Pinheiro, \\ Francisca Elisangela Lima, Thelma Araújo, Camila Moreira \\ Department of Nursing, Federal University of Ceará, Fortaleza, Brazil \\ Email: camilabrasil@alu.ufc.br
}

Received 17 January 2014; revised 28 February 2014; accepted 15 March 2014

Copyright (C) 2014 by authors and Scientific Research Publishing Inc.

This work is licensed under the Creative Commons Attribution International License (CC BY). http://creativecommons.org/licenses/by/4.0/

c) (i) Open Access

\begin{abstract}
This study aimed to analyze the references of articles with the approach to Health Education, published in Brazilian journals of nursing classified as Qualis Nursing A1 and A2. Descriptive study. Setting: SciELO library. We analyzed the references of 113 articles which were used to study the theoretical and methodological framework of bibliometrics, which aimed to promote subsidies for obtaining evaluation indicators of production, contributing to the expansion of scientific knowledge produced and disseminated among authors and researchers in nursing science. The main results showed the prevalence of article such as document most often quoted, references with 5 - 9 years of temporality, from Brazil and in Portuguese. The journals most frequently used were the Revista Brasileira de Enfermagem e a Revista Latino Americana de Enfermagem. Provided a vision of what is being referenced in nursing publications in Brazil, with regard to the Health Education.
\end{abstract}

\section{Keywords}

Nursing; Bibliometrics; Scientific; Health Education

\section{Introduction}

This study presents a bibliometric analysis of references used in articles approaching Health Education, published in nursing journals. Being a nurse involves implementing health education as an essential component of their work, acting as a caregiver and a facilitator of the educational process, not only in the classical information transfer, but also stimulating the individual, family and community to reflect and adopt healthy lifestyles.

As regards to the bibliometric technique, we emphasize that citations and the scientific communication systems are essential for science. They form a web of information that assists in the communication process of 
scientific activities, so that citations establish the authorship idea, and references allow identifying the document where the citation comes from. Therefore, the advances in scientific knowledge depend mostly on registering the research findings to allow the later citation by other researchers and provide opportunities for ideas evaluation and exchange among scientists. Furthermore, they help to promote the advances in scientific knowledge and prevent the duplication of efforts in research development [1].

We can divide the ways of communicating the results of scientific research into two types: "scientific communication" when directed to the general public and "scientific dissemination" when directed to the scientific community [2] [3]. In this article, we approach scientific dissemination, which takes place mainly through specialized journals. In recent years, most of the dissemination of research findings was published in indexed journals, with bibliometric studies seen as essential tools for characterization and evaluation [4].

The importance of bibliometric studies lays on the need to understand and evaluate the productivity and quality of researches, allowing detecting citation behavior patterns in scientific production [5]. These patterns help us understand how scientific knowledge is disseminated and incorporated among the authors and the general public, as well as identifying and collecting information about the scientific production and knowledge perpetuating mechanisms in their most diverse areas [6].

In the early 60's, the journal's impact factor was created. The Journal Citation Reports (JCR), which is a measure created by the Institute for Scientific Information (ISI) to evaluate the number of citations to articles from a journal in other journals indexed in this database [7]. The Coordination for the Improvement of Higher Education Personnel (CAPES) uses another evaluation method, which evaluates the quality of the intellectual production of a graduate program through stratification of journals-Qualis. It classifies journals as: A1, the highest; A2; B1; B2; B3; B4; B5; and C, zero weight [8]. For the analysis performed in this study, we will consider the Nursing journals classified as A1 and A2 Qualis/CAPES.

Analyzing the scientific production involves a significant set of bibliometric indicators. These can be divided into indicators of production (number of articles, authors, journals), communication and dissemination (analysis of bibliographic information databases and of literature distribution), consumption (analysis of references) involved in this study, and repercussion (analysis of citations) of publications and the information they hold [9].

Studies of consumption analysis of bibliographic references have been more widespread in the communication area [1] [10], and are mostly related to dissertations and theses. However, the bibliometric technique has limitations in the nursing field, since the studies evaluate strictly the structural and qualitative components of scientific papers, without analyzing the studies that supported such papers [11] [12].

Through this bibliometric research, we aim to support the obtaining of evaluation indicators of the productions, contributing to the expansion of scientific knowledge produced and disseminated among authors and researchers in scientific nursing. Therefore, this study aims to analyze the references used in articles that address Health Education, published in Brazilian journals of nursing, ranked as A1 and A2 Qualis Nursing.

\section{Method}

We used the theoretical-methodological framework of bibliometrics in this descriptive retrospective study. It represents a type of research that aims to quantify the written communication processes, supporting the formulation of science and technology policy in different areas of knowledge [13].

This survey took place in the Scientific Electronic Library Online (SciELO) database, which comprises a selected collection of Ibero-American scientific journals. SciELO envisages the development of a common methodology for the preparation, storage, dissemination and evaluation of scientific literature in electronic format. Among its specific goals is the design of bibliometric indicators [14].

The journals selection obeyed the following inclusion criteria: ranked as A1 and A2 Qualis Nursing-according to the evaluation for 2012; in the area of nursing concentration; and published in Brazil. It is worth mentioning that, for the journals selection we considered the Qualis Nursing evaluation for 2012, regardless of the variation experienced in previous years.

Therefore, with A1 Qualis, only the Latin American Journal of Nursing met the abovementioned criteria. As for the journals classified as A2, there were Acta Paulista de Enfermagem, Brazilian Journal of Medical and Biological Research, Cadernos de Saúde Pública, Memórias do Instituto Oswaldo Cruz, Revista Brasileira de Enfermagem, Revista da Escola de Enfermagem da USP, Revista de Saúde Pública, and Texto \& Contexto Enfermagem. 
Thus, we established the article selection criteria, namely: addressing Health Education; published from 2008 to 2013; with full-text available online; and in Portuguese, Spanish or English language. The editorials, commentaries and previous notes were excluded from this study.

For the articles selection, first we accessed each journal through SciELO database. Once in the virtual environment of the journals, we used the basic research form of SciELO and checked, in the index field, the term "Health Education" with the desired years of publication. To perform the association of the term "Health Education" with the years, we used the Boolean operator "and" and the operator "or" for any of the years ranging from 2008 to 2013.

After the survey, we obtained 113 articles to have their references analyzed. They presented the following distribution: Latin American Journal of Nursing (17), Acta Paulista de Enfermagem (14), Cadernos de Saúde Pública (8), Revista Brasileira de Enfermagem (25), Revista da Escola de Enfermagem da USP (16), Revista de Saúde Pública (11), and Texto \& Contexto Enfermagem (22). We did not find any relevant articles in the Brazilian Journal of Medical and Biological Research and in Memórias do Instituto Oswaldo Cruz.

Data collection happened in February 2014. We analyzed the references of the selected articles according to bibliometric data regarding the document type (article, book, thesis, dissertation and others-annals, reports, standards, bibliographies, laws and decrees), year of publication, temporality (time difference in years between the publication date of the reference cited and the publication date of the article), country of publication, language, name of the journal concerning the article cited, and the higher education institution for theses or dissertations cited.

To analyze these variables, we used the descriptive statistics with the software Statistical Package for Social Sciences (SPSS) version 20.0. We present the data in tables, containing the absolute and relative frequencies, which we later discussed through the pertinent literature on the topic in study.

\section{Results}

Next, we describe the data from the bibliographic references analyzed.

As verified in Table 1, we obtained the association between several types of documents cited, totaling 2223. Of these, the most frequently used types concerned articles, accounting for 1222 (55.0\%), and books with 666 (30.0\%). Theses and dissertations presented low representativeness, 80 (4.0\%), if considered together, possibly due to the preference of using derived articles and not the primary source, as well as for the difficulty of access.

The grouping of references according to their temporality revealed the prevalence of papers published in the period of 5 - 9 years for 934 (42.0\%), and of 0 - 4 years for 600 (27.0\%). About $18 \%$ of the references were cited with 10 - 14 years of publication, others fit in time intervals ranging from 15 to 35 years.

With regard to the geographic origin of the documents, Brazil was the most present, in 1734 (78.0\%), since it consisted of citations used in Brazilian journals, followed by 274 (12.3\%) of the United States, and 100 (4.5\%) of Great Britain. Besides the country of origin, we also included in this current analysis the language displayed in the reference, verifying the predominance of Portuguese in 1723 (77.5\%), and English in 455 (20.4\%).

As for the universities that originally published the dissertations and theses referenced in the articles, the research institutions located in the Southeast and South Region of Brazil had greater representation, followed by the Northeast. The six major universities comprised the following distribution: 22 (27.5\%) productions from the Universidade de São Paulo (USP), 14 (17.5\%), from the Universidade Federal de Santa Catarina (UFSC), 07 (8.7\%) from the Universidade Federal do Rio Grande do Norte (UFRN), 06 (7.5\%) from the Universidade Federal de Minas Gerais (UFMG), 06 (7.5\%) from the Universidade Federal do Rio Grande do Sul (UFRS), and 05 (6.2\%) from the Fundação Oswaldo Cruz (FIOCRUZ).

In regard to the journals that published the cited articles, despite the multitude involved, we identified a higher presence of the Revista Brasileira de Enfermagem with 90 (8.7\%) articles, the Latin American Journal of Nursing with 80 (7.8\%), and 73 (7.1\%) from Cadernos de Saúde Pública, as presented in Table 2.

Comparing the language of the documents cited and their country of origin in Table 3, we observe that almost all, 1664 (96.0\%), the Brazilian publications ( $\mathrm{n}=1734)$ were in Portuguese, $59(3.4 \%)$ in English, and $10(0.6 \%)$ in Spanish language. The English language was the most significant among the publications of other countries. Of the 467 publications in English, 252 (54.0\%) came from the United States, and 96 (20.5\%) from Great Britain, demonstrating the great influence of the United States. Brazil has contributed with 59 (12.6\%) of the total publications in English language, which was greater than the rest of Latin America, with only two (0.4\%), 
Table 1. Structural aspects of the references analyzed.

\begin{tabular}{|c|c|c|}
\hline Variables $(n=2223)$ & $\mathbf{N}$ & $\%$ \\
\hline \multicolumn{3}{|l|}{ Document type } \\
\hline Article & 1222 & 55.0 \\
\hline Book & 666 & 30.0 \\
\hline Thesis & 44 & 1.9 \\
\hline Dissertation & 46 & 2.1 \\
\hline Others & 245 & 11.0 \\
\hline \multicolumn{3}{|l|}{ Temporality (years) } \\
\hline $0-4$ & 600 & 27.0 \\
\hline $5-9$ & 934 & 42.0 \\
\hline $10-14$ & 400 & 18.0 \\
\hline $15-19$ & 155 & 7.0 \\
\hline $20-24$ & 66 & 3.0 \\
\hline $25-29$ & 24 & 1.1 \\
\hline $30-34$ & 36 & 1.6 \\
\hline$>35$ & 7 & 0.3 \\
\hline \multicolumn{3}{|l|}{ Geographic origin } \\
\hline Brazil & 1,734 & 78.0 \\
\hline United States & 274 & 12.3 \\
\hline Great Britain & 100 & 4.5 \\
\hline Switzerland & 18 & 0.8 \\
\hline Portugal & 17 & 0.7 \\
\hline Spain & 17 & 0.7 \\
\hline Other countries & 63 & 3 \\
\hline \multicolumn{3}{|l|}{ Language } \\
\hline Portuguese & 1723 & 77.5 \\
\hline English & 455 & 20.4 \\
\hline Spanish & 43 & 2.0 \\
\hline Other languages & 2 & 0.1 \\
\hline
\end{tabular}

Table 2. Distribution of references cited in the articles according to the journal.

\begin{tabular}{lcc}
\hline Journals (n = 1027) & n & \% \\
\hline Revista Brasileira de Enfermagem & 90 & 8.7 \\
Latin American Journal of Nursing & 80 & 7.8 \\
Cadernos de Saúde Pública & 73 & 7.1 \\
Revista Texto e Contexto Enfermagem & 64 & 6.2 \\
Ciência e Saúde Coletiva & 37 & 3.6 \\
Revista da Escola de Enfermagem da USP & 38 & 3.7 \\
Revista de Saúde Pública & 36 & 3.5 \\
Interface: Comunicação, Saúde e Educação & 27 & 2.6 \\
Diabetes Care & 20 & 1.9 \\
Acta Paulista de Enfermagem & 23 & 2.2 \\
Others & 539 & 52.7 \\
\hline
\end{tabular}


Table 3. Country of publication of the documents cited in the articles according to the language.

\begin{tabular}{cccccccccccc}
\hline & \multicolumn{2}{c}{ Portuguese } & \multicolumn{2}{c}{ English } & \multicolumn{2}{c}{ Spanish } & \multicolumn{2}{c}{ Italian } & \multicolumn{2}{c}{ French } & Total \\
\hline Country & $\mathbf{n}$ & $\mathbf{\%}$ & $\mathbf{n}$ & $\mathbf{\%}$ & $\mathbf{n}$ & $\%$ & $\mathbf{n}$ & $\%$ & n & $\%$ & \\
\hline Brazil & 1664 & 96.0 & 59 & 3.4 & 10 & 0.6 & - & - & - & - & 1734 \\
United States & 14 & 5.0 & 252 & 92.0 & 7 & 2.5 & 1 & 0.5 & - & - & 274 \\
Great Britain & 3 & 3.0 & 96 & 96.0 & 1 & 1.0 & - & - & - & - & 100 \\
Switzerland & 1 & 6.0 & 16 & 88.0 & 1 & 6.0 & - & - & - & - & 18 \\
Portugal & 17 & 100 & - & - & - & - & - & - & - & - & 17 \\
Spain & 1 & 7.1 & 1 & 7.1 & 15 & 85.8 & - & - & - & - & 17 \\
Others & 7 & 10.0 & 43 & 68.4 & 13 & 20.8 & - & - & 1 & 0.8 & 63 \\
Total & 1707 & 77.0 & 467 & 21.0 & 47 & 2.1 & 1 & 0.05 & 1 & 0.05 & 2223 \\
\hline
\end{tabular}

France and Germany also had two $(0.4 \%)$ publications each, and Italy had three $(0.6 \%)$ (these countries are included in the "Others" category of Table 3). Seeking a greater internationalization, the Brazilian journals tend to publish their articles in English; however, among the 2,223 references analyzed, there were only 59 (12.6\%) papers published in this language in Brazil.

The results from the association between document type and temporality (Table 4) revealed the increased use of recent citations, especially of articles, where 403 (33.0\%) had 0 - 4 years of publication. In all document types, there was a greater incidence of 5 - 9 years of publication.

Also on this analysis, we verified 374 (56.0\%) citations to books with temporality equal to or greater than 10 years. Compared to other productions, such reality obtained the following distribution: 281 (23.0\%) articles, 14 (32.0\%) theses, 09 (25\%) dissertations, and others with 83 (33.8\%). Therefore, books corresponded to the oldest publications cited.

By associating the document type with language of publication (Table 5), we noted greater internationalization of the articles, in 410 (33.5\%) cases. For other documents, the access to an international database may constitute an obstacle to its citation. The articles already overcame this reality, since they are electronically available and indexed in databases.

\section{Discussion}

In this study, there was a prevalence of citations of articles, followed by books, thus corroborating a study on collective health [6]. This finding may be due to the greater access to scientific productions in the last decade, given to the diversity of electronic journals and indexing in different databases with full-text articles available for researchers, enabling an easy consult to the publications by those interested in the subject [15].

Another situation where one must consider in the use of articles concerns the fact that some journals standards required the citation of publications from the own journal to which the article was submitted, as well as the fact, the theme "Health Education" gathers a rich collection of publications available, thus facilitating its use.

Although we identified that the books represent a document type cited less than articles, we noted the importance they still have, making its use significant in publications in the area of Health Education.

When analyzing temporality, we highlighted the interval of 5 to 9 years, which can relate to the fact the standards of the journals analyzed request citations around 5 to 10 years on average. It is worth remembering that books were the oldest type of document cited, which explains the stimulus and preference of journals for citations from scientific articles, due to the greater innovation and knowledge turnover.

Citations of published articles vary in time, there are subareas where they started being cited after four years of publication, and others where citations rise strongly from the year of publication, peaking two to six years after, when then begin to decline [16] [17].

In areas where we verify faster advances, researchers tend to cite recent studies, the opposite situation happens in areas with slow advances. The counting of citations, for the impact factor of scientific journals, is performed in the last two years, favoring areas that cite most recent documents [18].

When analyzing the geographic origin of citations, Brazil stood out among the several countries, which might result from the Brazilian nationality of researchers and journals, and since these request citations of the own 
Table 4. Types of documents cited in articles according to temporality of publication.

\begin{tabular}{|c|c|c|c|c|c|c|c|c|c|c|c|c|c|c|c|c|c|}
\hline \multicolumn{18}{|c|}{ Temporality (years) } \\
\hline & \multicolumn{2}{|c|}{$0-4$} & \multicolumn{2}{|c|}{$5-9$} & \multicolumn{2}{|c|}{$10-14$} & \multicolumn{2}{|c|}{$15-19$} & \multicolumn{2}{|c|}{$20-24$} & \multicolumn{2}{|c|}{$25-29$} & \multicolumn{2}{|c|}{$30-34$} & \multicolumn{2}{|c|}{$>35$} & \multirow[t]{2}{*}{ Total } \\
\hline $\begin{array}{l}\text { Document } \\
\text { type }\end{array}$ & $\mathbf{n}$ & $\%$ & $\mathbf{n}$ & $\%$ & $\mathbf{n}$ & $\%$ & $\mathbf{n}$ & $\%$ & $\mathbf{n}$ & $\%$ & $\mathbf{n}$ & $\%$ & $\mathbf{n}$ & $\%$ & $\mathbf{n}$ & $\%$ & \\
\hline Article & 403 & 33.0 & 538 & 44.0 & 195 & 16.0 & 55 & 4.5 & 12 & 1.0 & 12 & 1.0 & 7 & 0.5 & - & - & 1222 \\
\hline Book & 113 & 17.0 & 261 & 39.1 & 143 & 21.5 & 64 & 9.6 & 40 & 6.0 & 10 & 1.5 & 28 & 4.2 & 7 & 1.1 & 666 \\
\hline Thesis & 10 & 22.0 & 20 & 46.5 & 10 & 22.0 & 4 & 9.5 & - & - & - & - & - & - & - & - & 44 \\
\hline Dissertation & 11 & 22.7 & 26 & 56.8 & 5 & 11.4 & 3 & 6.8 & 1 & 2.3 & - & - & - & - & - & - & 46 \\
\hline Others & 63 & 25.8 & 99 & 40.6 & 39 & 15.8 & 24 & 9.2 & 11 & 4.8 & 8 & 3.3 & 1 & 0.5 & - & - & 245 \\
\hline Total & 600 & 27.0 & 944 & 42.4 & 392 & 17.6 & 150 & 6.7 & 64 & 3.0 & 30 & 1.4 & 36 & 1.6 & 7 & 0.3 & 2223 \\
\hline
\end{tabular}

Table 5. Types of documents cited in articles according to the language of publication.

\begin{tabular}{|c|c|c|c|c|c|c|c|c|c|c|c|}
\hline \multirow[b]{3}{*}{ Document type } & \multicolumn{10}{|c|}{ Language } & \multirow{3}{*}{ Total } \\
\hline & \multicolumn{2}{|c|}{ Portuguese } & \multicolumn{2}{|c|}{ English } & \multicolumn{2}{|c|}{ Spanish } & \multicolumn{2}{|c|}{ Italian } & \multicolumn{2}{|c|}{ French } & \\
\hline & $\mathbf{n}$ & $\%$ & $\mathbf{n}$ & $\%$ & $\mathbf{n}$ & $\%$ & $\mathbf{n}$ & $\%$ & $\mathbf{n}$ & $\%$ & \\
\hline Article & 812 & 66.5 & 379 & 31.0 & 31 & 2.5 & - & - & - & - & 1222 \\
\hline Book & 612 & 91.9 & 45 & 6.8 & 7 & 1.2 & 1 & 0.5 & 01 & 0.5 & 666 \\
\hline Thesis & 43 & 97.6 & 1 & 2.4 & - & - & - & - & - & - & 44 \\
\hline Dissertation & 46 & 100 & - & - & - & - & - & - & - & - & 46 \\
\hline Others & 207 & 84.7 & 31 & 12.6 & 7 & 2.8 & - & - & - & - & 245 \\
\hline Total & 1720 & 77.5 & 456 & 20.3 & 45 & 2.1 & 1 & 0.1 & 1 & 0.1 & 2223 \\
\hline
\end{tabular}

journals for theirs publications, which are mostly in Portuguese. Despite the productions of some journals being available in three languages (English, Portuguese and Spanish), it is worth mentioning that in Brazil there is a consumption of articles in the vernacular language, because most nurses do not master the English language [15].

The results of the language analysis point to a significant trend in the use of references in Portuguese, which restricts the dissemination of knowledge to countries that do not dominate this language. The low percentage of references in English suggests that language is still a barrier for Brazilian researchers when it comes to researches published in international journals, considering that even countries that do not have English as the official language also publish in this language in order to extend their results worldwide.

The use of international references values the productions, as it improves the scientific bases, contextualized with different realities, besides globalizing the scientific knowledge produced anywhere in the world.

The internationalization of articles was also evident in exploratory analysis studies of citations used in theses and dissertations in Public Health. The authors noted the prevalence of Portuguese language in the different types of documents, with the exception of journal articles, where the English language prevailed [19].

The evaluation of researchers and institutions, through the number of articles published in journals indexed in major databases and with higher impact factor, contributes to the increase of articles submission to journals of international scope [20]. Despite this stimulus to international publication, the dissemination of articles in national journals might be more appropriate, like in the case of issues of specific interest to a country or targeted audience, which researchers should take into account [21].

Researches in the area of nursing education in Brazil have advanced greatly with the creation and consolidation of research groups over the last decade. These advances meet the trends of the stricto sensu nursing graduate programs, which play a key role in stimulating the scientific development [22]. The results concerning Higher Education Institutions are due to the greater number of nursing graduation courses in the South (1035) and Southeast Region (2542) of Brazil, and also the greater amount of research groups in these two regions [22] [23].

The Revista Brasileira de Enfermagem (REBEn) stood out in publications involving Health Education, since 
the journal disseminates the scientific production in different areas of knowledge that are of interest to Nursing. It is a publication of the Associação Brasileira de Enfermagem (ABEn), which brings together partners all over the country and represents the largest and most traditional dissemination among nurses. The inclusion in SciELO collection, in September 2008, assured the visibility and internationalization of REBEn, attracting the interest of foreign authors, mainly Latin Americans [24].

The Latin American Journal of Nursing comes in second place, and it publishes mainly articles for the dissemination of original results of recent researches. It is a scientific publication of the Escola de Enfermagem de Ribeirão Preto (EERP), Universidade de São Paulo (USP), and it has been recently ranked as the only Brazilian nursing journal with A1 Qualis Nursing, giving greater rigor in the selection criteria for publications and support in the scientific community [25].

The evaluation of references cited in articles published only between 2008 and 2012 represented a limitation for this study, since it may not show possible evolutionary changes in patterns of publication, given the short period considered, thus requiring further studies that address a broader time interval. Another limitation we must consider concerns the analysis restricted to the language displayed in the reference, without checking if the same production was published in other languages, which would strengthen the process of worldwide scientific dissemination.

\section{Conclusions}

This study enabled us to visualize what the nursing publications in Brazil are referencing, with regard to Health Education. As health professionals, there was a commitment to strengthen the body of nursing knowledge, developing researches that contributed to both growth and consolidation of knowledge in the profession.

Analyses represent a major technological methodology for nursing, as they unfold research patterns and identify trends. Using the resources available in SciELO database proves to be interesting for the construction of the study, besides enabling future researches that analyze other indicators.

The results achieved in this study focused on characterizing the references pattern of Brazilian journal articles in the field of nursing, addressing Health Education. Based on that, we identified the following profile: journal articles constituted the main vehicle used in the preparation of articles; there was a higher prevalence of referenced documents in those published within 5 - 9 years of publication of the article source; the Portuguese language was predominant in the different types of documents cited; most documents referenced originated from Brazil; regarding the journals in which the articles cited were published, there was a greater presence of the $R e$ vista Brasileira de Enfermagem, Latin American Journal of Nursing, and Cadernos de Saúde Pública.

For further studies, we suggest investigating whether the profile of results found remains over time, or if it will undergo changes, and if they are similar in other fields of knowledge.

\section{Conflict of Interest Statement}

None declared.

\section{References}

[1] Mesquita, R.M.A. and Stumpf, I.R.C. (2004) Estudo de citações de documentos eletrônicos on-line em revistas da área de comunicação (Study Quotes Electronic Documents Online Journals of Communication). Em questão, 10, 261-274.

[2] Sánchez-Mora, A.M. (2003) A divulgação da ciência como literatura. Editora UFRJ, Rio de Janeiro, 112.

[3] Zamboni, L.M.S. (2001) Cientistas, jornalistas e a divulgação científica: Subjetividade e heterogeneidade no discurso da divulgação científica. Campinas: Autores Associados/Fundação de Amparo à Pesquisa do Estado de São Paulo, 53.

[4] Araújo, C.A. (2006) Bibliometria: Evolução histórica e questões atuais (Bibliometrics: Historical and Current Issues). Em Questão, 12, 11-32.

[5] Vanti, N.A.P. (2002) From Bibliometry to Webometry: A Conceptual Exploration of Several Forms of Measuring Information and Knowledge. Ciência da Informação, 31, 369-379.

[6] Carvalho, L.F. (2005) Bibliometria e saúde coletiva: Análise dos periódicos Cadernos de Saúde Pública e Revista de Saúde Pública (Bibliometrics and Public Health: Analysis of Journals Cadernos de Saúde Pública and the Revista de Saúde Pública). National School of Public Health Sérgio Arouca, Brazil.

[7] Elsaie, M.L. and Kammer, J. (2009) Impactitis: The Impact Factor Myth Syndrome (Short Communication). Indian 
Journal of Dermatology, 54, 83-85. http://dx.doi.org/10.4103/0019-5154.48998

[8] Coordenação de Aperfeiçoamento de Pessoal de Nível Superior (CAPES) (2012) Qualis periódicos. http://www.capes.gov.br/avaliacao/qualis

[9] López-Piñero, J.M. and Terrada, M.L. (1992) Los indicadores bibliométricos y la evaluación de la actividad médicocientífica (Bibliometric Indicators and Evaluation of Scientific and Medical Activity). Medicina Clínica (Barc), 98,142-148.

[10] Vanz, S.A.S. (2004) A produção discente em comunicação: Análise das citações das dissertações defendidas nos programas de pós-graduação do Rio Grande do Sul (dissertação) (A Student Production in Communication: Analysis of Citations of Dissertations Programs Graduate of Rio Grande do Sul). School of Library and Education of the Federal University of Rio Grande do Sul, Brazil.

[11] Ravelli, A.P.X., Fernandes, G.C.M., Barbosa, S.F.F., et al. (2009) The Production of Knowledge in Nursing: Bibliometric Study. Texto \& Contexto Enfermagem, 18, 506-512. http://dx.doi.org/10.1590/S0104-07072009000300014

[12] Merighi, M.A.B., Gonçalves, R. and Ferreira, F.C. (2007) Bibliometric Study on Nursing Theses and Dissertations Employing a Phenomenological Approach: Tendency and Perspectives. Revista Latino-Americana de Enfermagem, 15, 645-650. http://dx.doi.org/10.1590/S0104-11692007000400019

[13] Idczak, S.E. (2007) I Am a Nurse: Nursing Students Learn the Art and Science of Nursing. Nursing Education Perspectives, 28, 66-71.

[14] Packer, A.L., Bijone, M.R., Arati, A., et al. (2001) SciELO: A Methodology for Electronic Publishing. Revista Española de Salud Pública, 75, 291-312.

[15] Draganov, P.B., Friedländer, M.R. and Sanna, M.C. (2011) Andragogy in Health: Bibliometric Study. Escola Anna Nery Revista de Enfermagem, 15, 149-156. http://dx.doi.org/10.1590/S0104-11692007000400019

[16] Magri, M.H. and Solari, A. (1996) The SCI Journal Citation Reports: A Potential Tool for Studying Journals? Description of the JCR Journal Population Based on the Number of Citations Received, Number of Source Items, Impact Factor, Immediacy Index and Cited Half-Life. Scientometrics, 35, 93-117. http://dx.doi.org/10.1007/BF02018235

[17] Metcalfe, N.B. (2002) Journal Impact Factors. Nature, 376, 720. http://dx.doi.org/10.1038/376720b0

[18] Umbelino, F.M.B.C. (2009) Impact Factor of Scientific Journals in the Nursing Area. Rev Referência, 2, 95-100.

[19] Noronha, D.P. (1998) Análise das citações das dissertações de mestrado e teses de doutorado em saúde pública (1990-1994): Estudo exploratório (Analysis of Citations of Dissertations and Doctoral Theses in Public Health (1990-1994): An Exploratory Study). Ciência da Informação, 27, 66-75.

[20] Luz, M.P., Nascimento, A.L., Mendlowicz, M., et al. (2007) Brazilian Journal of Psychiatry: A Bibliometric Study of Articles Published from 1995 to 2004. Jornal Brasileiro de Psiquiatria, 56, $29-32$. http://dx.doi.org/10.1590/S0047-20852007000100008

[21] Victora, C.G. and Moreira, C.B. (2006) Scientific Publications and the North-South Relations: Editorial Racism? Revista de Saúde Pública, 40, 36-42. http://dx.doi.org/10.1590/S0034-89102006000400006

[22] Schveitzer, M.C., Backes, V.M.S., Lino, M.M., et al. (2011) Research Groups in Nursing Education: Characterization of Three Brazilian Regions. Texto \& Contexto Enfermagem, 20, 117-123. http://dx.doi.org/10.1590/S0104-07072011000500015

[23] Coordenação de Aperfeiçoamento de Pessoal de Nível Superior (CAPES) (2012) Mestrados/doutorados reconhecidos. http://conteudoweb.capes.gov.br/conteudoweb/ProjetoRelacaoCursosServlet?acao=pesquisarRegiao

[24] Marziale, M.H.P. and Mendes, I.A.C. (2002) The Impact Factor of Scientific Publications. Revista Latino-Americana de Enfermagem, 10, 466-467. http://dx.doi.org/10.1590/S0104-11692002000400001

[25] Nunes, E.C.D.A., Silva, L.W.S. and Pires, E.P.O.R. (2011) Nursing Professional Education: Implications of Education for Transpersonal Care. Revista Latino-Americana de Enfermagem, 19, 252-260. http://dx.doi.org/10.1590/S0104-11692011000200005 